\title{
System Reliability Based Design Optimization of Truss Structures with Interval Variables
}

\author{
Mohammad Zaeimi ${ }^{*}$, Ali Ghoddosain² \\ 1 Young Researchers and Elites Club, Science and Research Branch, Islamic Azad University, Tehran, Iran \\ 2 Faculty of Mechanical Engineering, Semnan University, 3513119111 Semnan, Iran \\ *Corresponding author, e-mail: mohammad.zaeimi@gmail.com
}

Received: 19 April 2019, Accepted: 31 October 2019, Published online: 16 December 2019

\begin{abstract}
New products ranging from simple components to complex structures should be designed to be optimal and reliable. In this paper, for the first time, a hybrid uncertain model is applied to system reliability based design optimization (RBDO) of trusses. All uncertain variables are described by random distributions but those lack information are defined by variation intervals. For system RBDO of trusses, the first order reliability method, as well as an equivalent model and the branch and bound method, are utilized to determine the system failure probability; and Improved $(\mu+\lambda)$ constrained differential evolution (ICDE) is employed for the optimization process. Reliability assessment of some engineering examples is proposed to verify our results. Moreover, the effect interval variables on the optimum weight of the truss structures are investigated. The results indicate that the optimal weight depends not only on the uncertainty level but also on the equivalent standard deviation; and a falling-rising behavior is observed.
\end{abstract}

Keywords

reliability based design optimization, interval variables, improved $(\mu+\lambda)$ constrained differential evolution (ICDE), structural optimization

\section{Introduction}

In traditional optimization procedure, most engineers assume that the design variables in the problem are deterministic. However, different kinds of uncertainties are presented and needed to be accounted for the design optimization process. Reliability based design optimization (RBDO) is a method that takes into account uncertainty due to the presence of random variables during the design process. The aim is to obtain a trade-off between a higher safety and a lower cost which is normally satisfied by setting a maximum allowed probability of failure [1]. In the real-world truss optimization problems, the source of uncertainty may be the variability of applied loads, spatial positions of nodes, and section and material properties [2].

Several attempts have been made in RBDO problems of truss structures by considering the displacement constraints and the stress limits of the components. Luo and Grandhi [3] proposed a reliability based multidisciplinary structural analysis for optimizing truss structures. Mathakari and Gardoni [4] developed a hybrid methodology by combining multi-objective genetic algorithms (MOGA) and finite element reliability analysis. The weight and reliability index of an electrical transmission tower are considered as the two objective functions for MOGA. The finite element reliability analysis performed by OpenSees software. Togan et al. [5] used the harmony search optimization algorithm and double-loop strategy to perform RBDO based on the reliability index and performance measurement approaches. Yand and Hsieh [6] solved the discrete and non-smooth RBDO problem by integrating subset simulation with a new particle swarm optimization algorithm (PSO). Shayanfar et al. [7] developed a double-loop strategy for reliability-based optimization of structures by employing genetic algorithm (GA) as an optimization approach and OpenSees software for finite element reliability analysis. A new hybrid method, namely the SORA-ICDE, was developed by HoHuu et al. [8] by integrating the sequential optimization and reliability assessment (SORA) with an improved constrained differential evolution algorithm (ICDE) for solving RBDO of engineering problems. Dizangian and Ghasemi [9] proposed a decoupled strategy for the reliable optimum design of trusses based on a design amplification factor combined with response surface method. Ho-Huu et al. [10] presented a new combination of an improved differential evolution 
algorithm and an inverse reliability analysis for solving RBDO problem of truss structures with frequency constraints. Young's modulus, mass density of the truss and the added masses were assumed to be the random design variables which have normal distribution. Hamzehkolaei et al. [11] proposed a decoupled RBDO method based on a safety factor concept, PSO and weighed simulation method. They showed that employing PSO as the search engine of RBDO and (weighed simulation method) WSM as the reliability analyzer provide more accurate results. In a similar study, they presented a method based on the hybrid improved binary bat algorithm (BBA) and weighed simulation method (WSM) for RBDO of truss structures with discrete-continuous variables [12]. Gomes and Corso [13] introduced a hybrid RBDO algorithm based on the genetic operations of GA, the position and velocity update of PSO for global exploration and the SQP for local search. They used FORM to account uncertainty in design and parameter variables. Stress, displacements, and frequency deterministic and probabilistic constraints were considered in this study. Ho-Huu et al. [14] proposed a global single-loop deterministic approach by combining a single-loop deterministic method (SLDM) and an improved different evolution (IDE), showed its capability to solve RBDO problems with both the continuous and discrete design variables. In SLDM, probabilistic constraints are converted to approximate deterministic constraints.

To solve RBDO of statically determinate truss structures, some studies can be found in the literature by modeling the structural system as a series system. Dimou and Koumousis [15] proposed a new version of GA, namely competitive GA, and showed its application to the reliability based optimal design of trusses. In a similar study, they utilized PSO algorithm instead of GA [16]. Togan and Daloglu [17] optimized a roof truss system by various optimization methods including sequential quadratic programming (SQP), evolution strategy (EVOL), and GA.

It should be noted that for a statically indeterminate truss, the assumption of a series system is inapplicable since the structural failure may occur after more than one component fail. To overcome this problem, some researchers modeled them as series-parallel systems and determined the failure of the system based on the failure paths concept. Hendawi and Frangopol [18] developed a probabilistic redundancy factor to estimate the first yielding of the structure. Natarajan and Santhakumar [19] utilized the branch and bound method and developed a formulation for RBDO of a transmission line towers. Thampan and Krishnamoorthy [20] proposed a modified branchand-bound (MBB) method to perform the system reliability assessment of truss structures. They coupled MBB and GA to minimize the total expected cost of the structure. Based on some fundamental assumptions, Park et al. [21] proposed an efficient technique to determine the system reliability of a complex structure directly from the reliabilities of its members. A single-loop method based on the matrix-based system reliability (MSR) technique was proposed by Nguyen et al. [22] to solve RBDO of a 6-member indeterminate truss structure. The MSR determines the probabilities of the system events by the matrix formulation. Liu et al. [23] proposed a system reliability based design optimization for truss structures by integrating GA and Monte Carlo simulation together with the trained radial basis function (RBF) neural networks. Okasha [24] considered nonlinear material behavior in RBDO problems of indeterminate trusses. The system reliability determined by weighted average simulation method (WASM), and the optimization process performed by using the firefly algorithm. Hamedani and Kalatjari [25] develop a logical framework, called RBO-S\&GTS, for system reliability analysis of truss structures and simultaneous size and geometry optimization of truss structures subjected to structural system reliability constraint. Csébfalvi [2] presented a new theoretical model and a problem-specific metaheuristic approach when the only source of uncertainty was the variability of the applied load directions; The varying load directions were handled as uncertain-but-bounded parameters. Benchmark results for this worst-load-direction oriented approach can be found in his other works $[26,27]$. By extending and revising their previous work [28], Lógó et al. [29, 30] proposed a new type of plastic limit design procedures and carried out reliability analysis of steel frames with limited residual strain energy capacity; where the influence of the limited load carrying capacity of the beam-to-column connections of elastoplastic frames multi-parameter static loading and probabilistically given conditions were taken into consideration.

As can be found from the previous studies, although they proposed some valuable and efficient methods in solving different kinds of RBDO problems, some key features in the design process of truss structures are ignored. On the one hand, most of the previous works are dealt with the statically determinate trusses, whereas statically indeterminate truss are more practical because the distribution of the applied between the structural members loads is done better and also some elements can be failed without 
compromising the viability of the structure [31]. On the other hand, research on solving the system RBDO problems of truss structures is focused on describing uncertainty by random distributions. However, finding precise random distributions require a large amount of information. Since in practical applications sufficient experimental samples are expensive and difficult to achieve, some assumptions should be made when using a probability model to perform the reliability analysis. However, several studies revealed that even a small deviation of the distribution parameters from the real values can result in very large errors in the reliability analysis [32].

In order to overcome this problem, two hybrid uncertain models have been proposed by integrating the traditional probability approach and the non-probability interval analysis. The concept of these models is based on the use of variation intervals in the face of insufficient uncertainty information. In this way, a more accurate reliability analysis can be achieved by eliminating errors from assumptions on the probability distributions [33].

In the first model, random variables with sufficient information and ones lacking enough uncertainty information are treated as random distributions and intervals, respectively. While in the second one, all random variables are described by random distributions but some key distribution parameters of them which lack information are defined by variation intervals. For a good overview about hybrid uncertain models, the interested reader is referred to the work by Jiang et al. [34].

For the first hybrid uncertain model, a number of studies have been published. Du et al. [35] proposed a single-loop RBDO to deal with the uncertain variables described by the mixture of probability distributions and intervals. Du [36] formulated a reliability analysis framework with the aim of investigating computational tools to determine the effects of random and interval inputs on direct and inverse reliability analysis results. By considering both random variables and interval variables, a sensitivity analysis method was proposed by Guo and Du [37]. They introduced six sensitivity indices based on the first-order reliability method (FORM) to investigate the sensitivity of the average reliability and reliability bounds. Based on the probabilistic reliability model and interval arithmetic, Qiu and Wang [38] developed a new model to improve interval estimation for reliability of the hybrid structural system. Jiang et al. [39] proposed an equivalent model for reliability analysis with random and interval variables. By changing the interval variables to corresponding uniform distributions, the original problem was converted into a conventional reliability analysis problem with only random variables. Xie et al. [40] proposed a new hybrid reliability analysis by decomposing the probability analysis loop and interval analysis loop into two separate loops. Furthermore, a new interval analysis method is formulated based on the monotonicity of limit-state function.

The second hybrid uncertain model was first proposed by Elishakoff and Colombi [41] by formulating an anti-optimization problem. Non-linear buckling of a column with initial imperfection was investigated by Elishakoff et al. [42] based on the probability and non-probability approaches. Moreover, they showed that the results from both of them were critically contrasted. Qiu et al. [43] proposed an approach to obtain the interval of the system failure probability from the statistical parameter intervals of the basic variables. Jiang et al. [33] proposed a new structural reliability analysis by conducting a monotonicity analysis for the probability transformation process, and two efficient algorithms were formulated based on the reliability index and performance measurement approach. In another work, they presented a detailed description of the effects of interval parameters on the limit state function [44]. Huang et al. [45] developed a decoupled RBDO algorithm by utilizing the reliability analysis presented in previous work by Jiang et al. [44] and an incremental shifting vector (ISV) technique.

In this paper, for the first time, the first hybrid uncertain model is considered to system RBDO problems of truss structures; and the effect of interval variables on the optimum weight of the structure is investigated which can be beneficial to select and define a proper variation intervals in the design process. The reliability analysis we use is based on the work by Jiang et al. [39] and the optimization process is performed by using the ICDE algorithm. The rest of this paper is organized as follows. Section 2 presents the ICDE algorithm. In Section 3 a brief description of the reliability assessment with and without interval variables, system reliability analysis for truss structures as well as reliability based design optimization are presented. Numerical and structural examples are proposed in Section 4. Finally, the conclusion is presented in Section 5.

\section{The improved $(\mu+\lambda)$ constraint differential evolution (ICDE) algorithm}

According to the relatively fast convergence rate, low standard deviation from the mean value in different runs of algorithm and ease of implementation [46], we used ICDE 
algorithm for optimization process in this study. ICDE is a robust version of differential evolution algorithm to solve the constrained optimization problem. Two main parts of ICDE are the improved $(\mu+\lambda)$ - differential evolution (IDE) and the archiving-based adaptive tradeoff model [47]. The next sections briefly introduce the main parts algorithm.

\subsection{Differential evolution (DE) algorithm}

The differential evolution (DE) was first developed by Storn and Price (1997). It is one of the most successful and widely used metaheuristic algorithms to solve continuous optimization problem. DE is a population-based algorithm which uses three evolutionary operators, i.e., mutation, crossover, and selection operators. Note that the diversity of the population is guaranteed by using the mutation and crossover operators. The main steps of DE algorithm are described below.

Step 1 - Generating initial population: In this step, an initial population containing $\mu$ parents are generated randomly in the search space as follows:

$$
\boldsymbol{X}_{i}^{t}=\boldsymbol{L} \boldsymbol{B}+\text { rand } .(\boldsymbol{U B}-\boldsymbol{L B}), \quad i=1,2, \ldots, \mu,
$$

in which $\boldsymbol{X}_{i}^{t}$ is the current individual in the $t$-th generation (in the initial population $t$ is equal to zero), rand is used to create a random number in [0,1] and $\boldsymbol{L} \boldsymbol{B}$ and $\boldsymbol{U} \boldsymbol{B}$ indicate the lower and upper bound of the design variables respectively.

Step 2 - Generating the mutant vectors: In each generation, mutant vectors $\boldsymbol{V}_{i}$ are generated based on the following four strategies [47]:

Rand/1:

$\boldsymbol{V}_{i}^{t}=\boldsymbol{X}_{r_{1}}^{t}+F \cdot\left(\boldsymbol{X}_{r_{2}}^{t}-\boldsymbol{X}_{r_{3}}^{t}\right)$

Rand/2:

$\boldsymbol{V}_{i}^{t}=\boldsymbol{X}_{r_{1}}^{t}+F \cdot\left(\boldsymbol{X}_{r_{2}}^{t}-\boldsymbol{X}_{r_{3}}^{t}\right)+F \cdot\left(\boldsymbol{X}_{r_{4}}^{t}-\boldsymbol{X}_{r_{5}}^{t}\right)$.

Current - to - rand/1:

$\boldsymbol{V}_{i}^{t}=\boldsymbol{X}_{i}^{t}+F \cdot\left(\boldsymbol{X}_{r_{1}}^{t}-\boldsymbol{X}_{i}^{t}\right)+F \cdot\left(\boldsymbol{X}_{r_{2}}^{t}-\boldsymbol{X}_{r_{3}}^{t}\right)$.

Current - to - best/1:

$\boldsymbol{V}_{i}^{t}=\boldsymbol{X}_{i}^{t}+F \cdot\left(\boldsymbol{X}_{\text {best }}^{t}-\boldsymbol{X}_{i}^{t}\right)+F \cdot\left(\boldsymbol{X}_{r_{1}}^{t}-\boldsymbol{X}_{r_{2}}^{t}\right)$,

where $r_{1}, r_{2}, r_{3}, r_{4}$ and $r_{5}$ are different integers selected from the set $\{1,2, \ldots, \mu\}$ and satisfy $\left\{r_{1} \neq r_{2} \neq r_{3} \neq r_{4} \neq r_{5}\right\}, \boldsymbol{X}_{\text {best }}^{t}$ and $\boldsymbol{X}_{i}^{t}$ are respectively the best and the current individual in $t$-th generation and scale factor $F$, is selected randomly between 0 and 1 . After generation of mutant vectors, they are checked against the boundary constraints and the following modification is performed:

$$
V_{i, j}^{t}=\left\{\begin{array}{cc}
2 X_{j}^{l}-V_{i, j}^{t} & \text { if } V_{i, j}^{t}<X_{j}^{l} \\
2 X_{j}^{u}-V_{i, j}^{t} & \text { if } V_{i, j}^{t}>X_{j}^{u} \\
V_{i, j}^{t} & \text { otherwise }
\end{array}\right.
$$

Step 3 - generating trial vectors by crossover operator: In this step, by using the binomial crossover, some elements of the current vector is replaced by some elements of mutant vector to produce the trial vector $\boldsymbol{U}_{\mathrm{i}}$ :

$$
U_{i, j}^{t}=\left\{\begin{array}{cc}
V_{i, j}^{t} & \text { if rand } \leq C R \text { or } j=j_{\text {rand }} \\
X_{i, j}^{t} & \text { otherwise }
\end{array} .\right.
$$

Step 4 - comparing the trial vector and current vector: Finally, the trial vector compare with the current vector according to their objective function values and the better one with better objective value will survive in the next generation:

$$
\boldsymbol{X}_{i}^{t+1}=\left\{\begin{array}{cc}
\boldsymbol{U}_{i}^{t} & \text { if } f\left(\boldsymbol{U}_{i}^{t}\right) \leq f\left(\boldsymbol{X}_{i}^{t}\right) \\
\boldsymbol{X}_{i}^{t} & \text { otherwise }
\end{array} .\right.
$$

\subsection{Improved $(\mu+\lambda)$ - differential evolution (IDE) algorithm}

The ICDE utilizes an improved version of the DE, called IDE, which have better population diversity. In IDE, the offspring population $Q_{t}$ is generated from the current population $P_{t}$ based on the following three steps. At the end of these steps, the offspring population will have $\lambda=3 \mu$ individuals.

Step 1: set $Q_{t}=\varnothing$;

Step 2: generate three offspring for each individual in $P_{t}$ :

- for the first offspring $\boldsymbol{y}_{1}$, use the "rand/1" mutation strategy and the binomial crossover;

- for the second offspring $\boldsymbol{y}_{2}$, use the "rand/2" mutation strategy and the binomial crossover;

- for the third offspring $\boldsymbol{y}_{3}$, use the "current-to-best/1" strategy and improved breeder genetic algorithm (iBGA) [47].

Step 3: update the offspring population,

$Q_{t}=Q_{t} \cup \boldsymbol{y}_{1} \cup \boldsymbol{y}_{2} \cup \boldsymbol{y}_{3}$;

In order to obtain a good balance between the population diversity and convergence of the population, two different mutation strategies are performed in the "current-to-rand/best/1" in step 2. In the first one, the "currentto-rand/1" strategy is used to increase the global search of the algorithm, while the second one increases the convergence rate of the population toward the global optimum. When the generation number is more than a threshold value, the second phase begins. 


\subsection{Archiving-based adaptive tradeoff model (ArATM)}

In constrained optimization, three possible situations may exist in a combined population, $H_{t}$, resulting from the combination of the offspring population $Q_{t}$ and the parent population $P_{t}$. These situations are the infeasible, semi-feasible and feasible situations and each of them has different constraint-handling method in the ArATM. By performing the procedure described below, ArATM simultaneously satisfies the constraints and optimizes the objective function of the problem.

In the infeasible situation, since all individuals violate the constraints, the population should be guided toward the feasible region very quickly to maintain the population diversity. For this purpose, the original problem transformed to a bi-objective optimization problem and a good tradeoff between two objectives, the objective function and the degree of constraint violation is made. Moreover, the individuals that have no chance to survive into the next generation will be stored in an archive to compete with the individuals of the next combined population $H_{t+1}$. In this way, the population diversity can be increased during the optimization process.

In the semi-feasible situation, the combined population contains both feasible and infeasible individuals. In this situation, the algorithm benefits from not only the feasible individuals but also some infeasible ones since they may have important information to find the global optimum. To fulfill this aim, by using an adaptive fitness transformation scheme, some feasible individuals with small fitness values along with some infeasible individuals with both small degree of constraint violation and small fitness values are selected to survive into the next generation.

In the feasible situation, all individuals are feasible and the comparison between them is performed only based on their fitness values. Therefore, those with better fitness value constitute the next population.

\section{Reliability and reliability based design optimization}

\subsection{Archiving-based adaptive tradeoff model (ArATM)}

The Failure probability of a limit state function (or failure mode) can be calculated using a probabilistic reliability analysis:

$P_{f}=P(G(X) \leq 0)=\int_{G(X) \leq 0} f_{X}(X) d X$,

where $P_{f}$ is the failure probability, $G(\boldsymbol{X})$ indicates the limit state function which is a function of random variables $\boldsymbol{X}$, and $f_{\boldsymbol{X}}(\boldsymbol{X})$ is the joint probability density function of $\boldsymbol{X}$. The reliability $R$ is defined as
$R=1-P_{f}$

Because of some difficulties in computing the above multi-dimensional integral [48], one of the most commonly used approximation methods called first order reliability method (FORM) is used in this study. The ease of the computational difficulties is provided through the simplifying the integrand $f_{x}(\boldsymbol{x})$ and approximating $G(\boldsymbol{X})$. First, the shape of the $f_{x}(\boldsymbol{x})$ is simplified by mapping $X$ into the independent standard normal space (i.e. U-space) [49]:

$\Phi\left(U_{i}\right)=F_{X_{i}}\left(X_{i}\right), U_{i}=\Phi^{-1}\left[F_{X_{i}}\left(X_{i}\right)\right], i=1,2, \ldots, n$,

in which $F_{X_{i}}$ and $\Phi^{-1}$ are cumulative distribution function (CDF) and inverse standard normal CDF, respectively. The limit state function can be written in U-space as follows

$G(X)=G(T(U))=G(U)$,

where $T$ indicates a probability transformation and $G(\boldsymbol{U})$ is the transformed limit sate function in the U-space. Note that, for transformation, methods such as Rosemblatt [49], Nataf [50] or linear [48] transformation can be used based on the correlation between the random variables. Next, the limit state function is approximated by the first order Taylor expansion at a point with the highest probability density on the limit state function in U-space [51]. Geometrically, it is a point, namely the most probable point (MPP), with the shortest distance from the origin of U-space to $G(\boldsymbol{U})=0$. This minimum distance determines the reliability index [52]:

$\left\{\begin{array}{c}\beta=\min _{U} U \\ \text { s.t. } G(U)=0\end{array}\right.$,

where $\beta$ is the reliability index. Now, failure probability in Eq. (9) can be determined by the following equation:

$P_{f}=\Phi(-\beta)$,

where $\Phi$ is the standard normal CDF. It should be noted that, In order to use FORM for variables with non-normal distribution, we can use their equivalent mean and equivalent standard deviation [53].

\subsection{Reliability analysis for random variables with both random and interval variables}

When both random and interval variables are involved in a structure, the limit state function $G(X)$ will be changed to $G(\boldsymbol{X}, \boldsymbol{Y})$ where $\boldsymbol{Y}$ is an $m$-dimensional vector containing all the interval variables [39]: 
$Y \in\left[Y^{L}, Y^{R}\right], Y_{i} \in\left[Y_{i}^{L}, Y_{i}^{R}\right] \quad i=1,2, \ldots, m$.

Therefore the limit state function is related to not only the random variables $\boldsymbol{X}$ but also the interval variables $\boldsymbol{Y}$. Moreover, due to the interval variables, the transformed limit state described by $\boldsymbol{G}(\boldsymbol{X}, \boldsymbol{Y})=0$ will not be a single surface, but a strip enclosed by two bounding surfaces $S_{L}$ and $S_{R}$.

$S_{L}: \min _{Y} G(X, Y)=0, \quad S_{R}: \max _{Y} G(X, Y)=0$

As shown in Fig. 1, $S_{L}$ and $S_{R}$ are respectively the lower and upper bounding surfaces of $\boldsymbol{G}(\boldsymbol{X}, \boldsymbol{Y})$ as $\boldsymbol{Y}$ changes. Jiang et al. [39] proposed that for each bounding surface, we can obtain reliability indexes through FORM and define a hybrid reliability index $\beta^{h}$ :

$\beta^{h} \in\left[\beta^{L}, \beta^{R}\right]$,

where $\beta^{L}$ and $\beta^{R}$ indicate the reliability index of the lower and upper bounding surfaces, respectively. $\beta^{h}$ is not a deterministic value but a possible variation range of the reliability index formed by interval parameters $\boldsymbol{Y}$. Moreover, the failure probability of the structure will belong to an interval.

$P_{f} \in\left[P_{f}^{L}, P_{f}^{R}\right]=\left[\phi\left(-\beta^{L}\right), \phi\left(-\beta^{R}\right)\right]$

Since a strict reliability requirement can be satisfied only by focusing on the worst case, our most concern in this study is practically the upper bound of this interval. Therefore, according to Eqs. (17) and (18), only $\beta^{L}$ or $P_{f}^{R}$ should be determined to show the reliability degree of a structure. By using Eqs. (13) and (16), the following optimization problem can be solved to compute $\beta^{L}$.

$\left\{\begin{array}{l}\beta^{L}=\min _{U} U \\ \text { subject to }: S_{L}=\min _{Y} G(U, Y)=0\end{array}\right.$

This problem can be decomposed into the following two-layer nesting optimization:

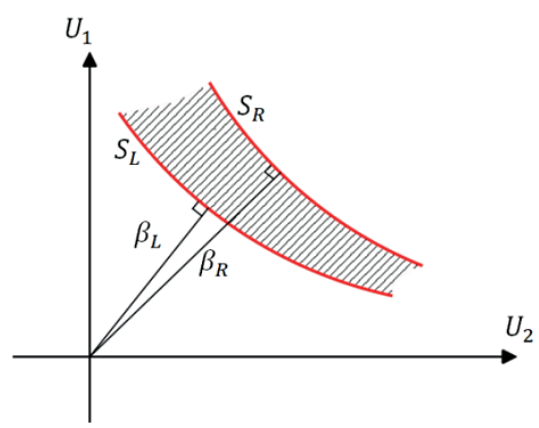

Fig. 1 Limit-state strip by considering the interval variables
Outer-layer optimization

$\left\{\begin{array}{l}\beta^{L}=\min _{U}\|U\| \\ \text { subject to } G\left(U, Y^{*}\right)=0\end{array}\right.$.

Inner-layer optimization

$\left\{\begin{array}{l}G\left(U, Y^{*}\right)=\min _{Y} G(U, Y) \\ \text { subject to } Y_{i}^{L} \leq Y_{i} \leq Y_{i}^{R}, \quad i=1,2, \ldots, m\end{array}\right.$.

The inner-layer optimization is used to find the extreme values of the limit-state function in terms of $Y$, and $\boldsymbol{Y}^{*}$ indicates the corresponding optimum values for interval variables. For practical engineering problems, solving the above nesting optimization leads to an extreme computational cost. Jiang et al. [39] proposed an equivalent model for the above hybrid reliability with both random and interval variables, which is a conventional reliability analysis problem with only random variables. Hence, only through evaluating the reliability of the equivalent model the original hybrid reliability can be easily computed.

Their equivalent model is based on changing the interval variables to corresponding uniform distributions. Therefore, a hybrid reliability problem with random variables $\boldsymbol{X}$ and interval variables $\boldsymbol{Y}$ can be changed to a conventional reliability problem with only random variables. By satisfying Karush-Kuhn-Tucker necessary condition [54], they mathematically proved that the original problem and the equivalent problem have a same solution of $\boldsymbol{X}$ and $\boldsymbol{Y}$ when using the FORM to compute their reliability.

\subsection{System reliability analysis for truss structures}

For a truss structure, a member fails when the internal force exceeds the strength of the member. It can be written as follows:

$G_{i}=R_{i} A_{i}-S_{i}$,

where $R_{i}$ is the allowable stress, $A_{i}$ and $S_{i}$ are respectively the cross sectional areas and the internal force of the $i$-th member. By using the FORM, failure probability of member $i$ can be evaluated as follows:

$P_{i}=P\left(G_{i} \leq 0\right)=\Phi\left(-\beta_{i}\right)$,

where $\beta_{i}$ is the reliability index for $i$-th member. The internal force vector can be formulated as [1]:

$S_{i}=\sum_{j=1}^{3 l} b_{i j} L_{j}$ 
where $L_{j}$ is the external load applied to the structure, $l$ is the number of nodes and $b_{i j}$ is the load coefficient of member $i$ with respect to $L_{j}$. For a statically determinate truss, $b_{i j}$ are constant while those of a statically indeterminate truss become functions of $A_{i}$. According to the nature of the structure, system failure occurs in parallel, series or a combination of both. For parallel failure, the system failure takes place when all failure modes in that system fail. While for series system, system failure results from the failure in any failure mode.

In case of a statically determinate truss, failure of the structure happens when any member fails. Therefore, the structural failure probability is estimated by modeling the structural system as a series system. However, in case of a statically indeterminate truss, estimating of the structural failure is very complex because failure of a member will not always result in failure of the whole system. In this case, we deal with a system composed of combinations of series and parallel subsystems. When failure of a member occurs, redistribution of loads takes place and thus the external loads are sustained by the members in survival. By repeating this process, system failure of the structure results when a specified number of members are failed and structure is turned into a mechanism. Failure of the structure is defined by investigating the singularity of the total structure stiffness matrix formed by the remaining members. After failure in $p$ members, by using the matrix method, stress analysis is carried out and the internal forces of the remaining members are determined as follows [1]:

$$
S_{i\left(e_{1}, e_{2}, \ldots, e_{p}\right)}=\sum_{j=1}^{3 l} b_{i j} L_{j}-a_{i e_{1}} r_{e_{1}}-\ldots-a_{i e_{p}} r_{e_{p}},
$$

where suffix $\left(e_{1}, e_{2}, \ldots, e_{p}\right)$ shows a failure path including a set of failed members and their sequential order of failure, $a_{i j}$ are the coefficients of influence and $r_{j}$ indicated the residual strength of the $j$-th failed member. It should be noted that, the residual strength for a member of a brittle material is zero, while for a member of a ductile material is equal to yield strength (in tension) or buckling strength (in compression).

In this study, we utilize one of the most popular approaches called branch and bound method, to find system failure probability of statically indeterminate trusses. It is based on the failure paths which result in a failure mode. In this method, lower and upper bounds of the structural failure probability are determined by selecting dominant failure paths and discarding the failure paths that have negligible occurrence probability.
Note that due to the large number of failure modes and the complexity of the calculation of the real statistical correlation between the failure modes, especially in the statically indeterminate truss structures, the Cornell's upper bound [55] is utilized to evaluate the system failure probability in this study for simplicity. However, for taking into account the real statistical correlation between the failure modes, Ditlevsen's bound can be used [56]. For statically determinate truss, it is equal to the sum of the failure probability of the members; while for statically indeterminate truss, it is equal to the sum of the upper bound of each failure path.

\subsection{Reliability based design optimization}

RBDO formulations can be classified into component and system reliability. In the first one, only one single structural member with a single failure mode is investigated. However, in a real structure, more than one member can fail because of the existence of a large number of possible failure modes. In order to obtain the second one, it is required to know the component reliability and the relationship between the system and its components. Optimization problem under the component reliability constraints can be stated as $[57,58]$ :

$$
\left\{\begin{array}{l}
\min W=\sum_{i=1}^{m} \rho L_{i} A_{i} \\
\text { Subject to }: P_{i} \leq P_{i}^{t}
\end{array}\right.
$$

where $W$ is the weight of the structure, $\rho$ is the density of the material, $L_{i}, A_{i}$ are the length and cross-section area of member $i$, respectively; $P_{i}$ and $P_{i}^{t}$ are respectively the failure probability and the target failure probability of member $i$. For system reliability based optimization, the above formulation can be expressed as follows:

$$
\left\{\begin{array}{l}
\min W=\sum_{i=1}^{m} \rho L_{i} A_{i} \\
\text { Subject to }: P_{s y s} \leq P_{s y s}^{t}
\end{array} .\right.
$$

In which $P_{s y s}$ and $P_{s y s}^{t}$ are the failure probability and the target failure probability of the system. RBDO is based on three parts, including structural analysis, optimization procedure and reliability analysis. The first one is needed to obtain the response of the structure; the second one is used to find the design variables with minimum objective function; and the last one is performed to compute the reliability constraints of the RBDO. There are different 
strategies in the literature to link these parts together, e.g., single-loop, double-loop and decoupled, each having its own advantages and disadvantages.

Single-loop and decoupled strategies, despite the acceptable computational efficiency, have some disadvantages that limit their usage. Both of them avoid the reliability analysis by defining equivalent optimality conditions. In single-loop strategies, the most probable point is approximated based on approximation methods such as lower-order polynomial functions or derivatives of the performance functions. Since they are approximation methods, there is no guarantee to obtain accurate results [6]. Decoupled strategies break the reliability analysis and the optimization procedure into sequential cycles. In these methods, the original problem is transformed to a deterministic optimization with constraints that are changed based on the reliability analysis cycle. They begin with a deterministic optimum and then try to find a close feasible solution satisfying the reliability constraint. When there exists multiple local optima and the reliable solution is not close to the deterministic optimum, they cannot provide satisfactory performance [6].

Although it suffers from the computational effort compared to other strategies, we use the double-loop strategy based on the reliability index approach (RIA) because of its simplicity and accuracy [59-61].

As shown in Fig. 2, the double-loop strategy is a nested optimization problem where the inner loop deals with reliability assessment and structural analysis, while the outer loop deals with the minimization of the objective function. In this work, we utilize ICDE optimization algorithm in the outer loop of the RBDO. The process of solving RBDO problems is briefly described with the following steps:

1. Generate an initial parent population $\left(P_{t}\right)$ with $\mu$ individuals, which are selected uniformly and randomly from the search space.
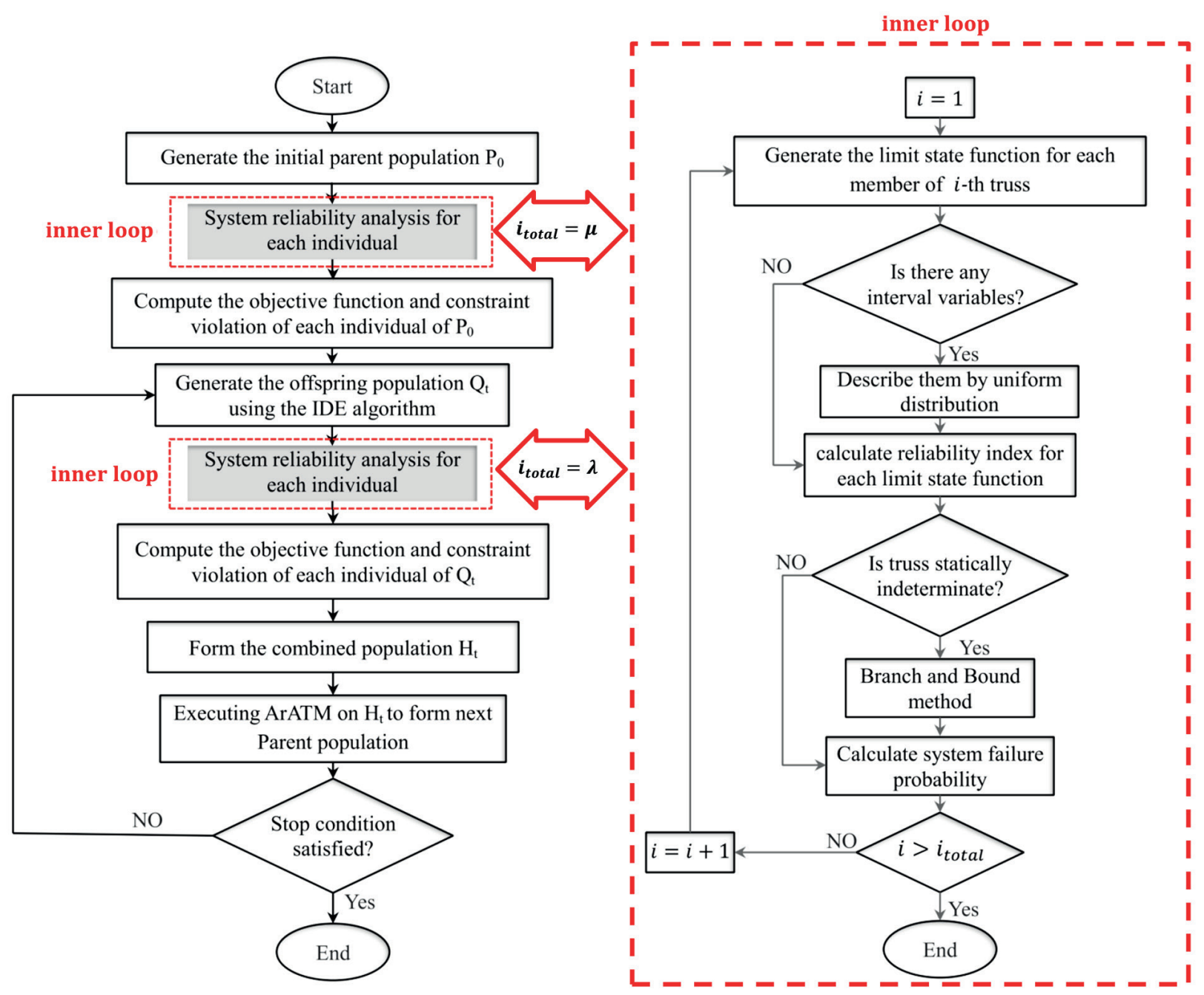

Fig. 2 Flowchart of RBDO using ICDE algorithm 
2. Perform the system reliability analysis for each individual as follows:

(i) Generate the limit state function for each member of the truss structure using Eqs. (22) and (25).

(ii) Using Eq. (13), calculate the reliability index (or probability of failure) for each limit state functions defined before. If there are interval variables, change them to their related uniform distributions.

(iii) Calculate the failure probability of the system using Cornell's upper bound.

3. Compute the objective function (i.e. weight of each individual or the truss structure), constraint violation (i.e. the difference between the maximum allowable of structural system failure probability and the failure probability of the system) for each individual.

4. Generate the offspring population $\left(Q_{t}\right)$ with $\lambda$ offspring by performing IDE on all the individuals in $P_{t}$ (see Section 2.2).

5. Execute step 2 for each individual in $Q_{t}$.

6. Combine $P_{t}$ with $Q_{t}$ to obtain a combined population $\left(H_{t}\right)$.

7. Select $\mu$ potential individuals from $H_{t}$ to form the next population by ArATM strategy (see Section 2.3).

8. Check the termination criterion. If it is not satisfied go to Step 4; otherwise, stop and output the best individual in $P_{t}$.

\section{Numerical results}

In this section, several engineering design problems taken from the literature are investigated. Since the execution of the system reliability analysis for each individual (i.e., each truss structure) in the double-loop strategy is a time consuming process, the inner loop (see Fig. 2) is performed in parallel. The computing machine used for this work consists of an Intel Xeon at $2.9 \mathrm{GHz}$ with 40 cores and $40 \mathrm{~GB}$ RAM. The ICDE algorithm is coded in MATLAB programming software and the parameters are set as follows: $\mu=$ 20, $C R=0.8, F=0.9$ and $\delta=0.0001 . \mu, C R, F$ and $\delta$ are the population size, the crossover control parameter, a uniformly distributed random number between 0 and 1 , and the tolerance value for the equality constraints respectively in the ICDE algorithm [39]. The optimization process will be terminated when there is no improvement of the solutions after 150 iterations. Note that, for all considered truss structure examples, failure of the members is assumed to occur under tension or compression. However, the allowable tension and compression stresses are taken to be the same.

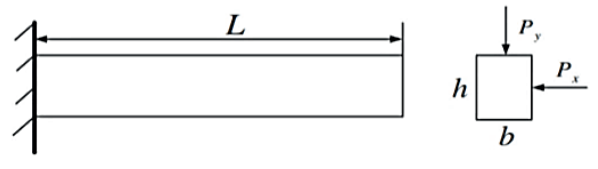

Fig. 3 A cantilever beam [39]

\subsection{Reliability assessment of engineering problems \\ 4.1.1 A cantilever beam}

As shown in Fig. 3, consider a cantilever beam which is Subjected to a horizontal force $P_{x}$ and a vertical force $P_{y}$. The limit state function according to maximum stress at the fixed end of the beam is defined as follows [39]:

$G\left(b, h, P_{x}, P_{y}\right)=S-\frac{6 P_{x} L}{b^{2} h}-\frac{6 P_{y} L}{b h^{2}}$,

where $b, h$ and $L$ indicate the width, height of the cross section and the length of the beam, respectively; $S$ denotes the yield strength which is equal to $320 \mathrm{MPa}$. As shown in Table 1, while $b, h$ and $L$ are random variables following normal distribution, $P_{x}$ and $P_{y}$ are treated as interval variables.

From the percentage values proposed in Table 2, it can be seen that our result is better than those reported in the previous studies.

The main reason why we obtain a smaller value for $\beta^{L}$ is that we utilize a robust meta-heuristic algorithm, ICDE, in this paper to solve Eq. (13); while in the previous studies a traditional gradient based algorithm, HL-RF, is used which can be most likely trapped in a local optimum solution.

\subsubsection{A cantilever tube}

In this example, the reliability analysis of a cantilever tube proposed in Fig. 4 is performed under three external loads $F_{1}, F_{2}$ and $P$, and a torsion $T$. The maximum von-Mises stress $\sigma_{\max }$ on the top surface of the tube at the origin should be less than a yield strength $S_{y}$. The limit state function is defined as follows [39]:

Table 1 Uncertain variables for the cantilever beam

\begin{tabular}{lccc}
\hline $\begin{array}{l}\text { Type of } \\
\text { variable }\end{array}$ & $\begin{array}{c}\text { Random } \\
\text { variables }\end{array}$ & $\begin{array}{c}\text { Distribution } \\
\text { parameter 1 }\end{array}$ & $\begin{array}{c}\text { Distribution } \\
\text { parameter 2 }\end{array}$ \\
\hline \multirow{3}{*}{ Normal } & $b(\mathrm{~mm})$ & 100 & $\boldsymbol{\sigma}$ \\
& $h(\mathrm{~mm})$ & 200 & $\mathbf{1 5}$ \\
& $L(\mathrm{~mm})$ & 1000 & $\mathbf{2 0}$ \\
\hline \multirow{3}{*}{ Interval } & & Lower bound & Upper bound \\
& $P_{x}(N)$ & 47000 & $\mathbf{5 3 0 0 0}$ \\
\hline
\end{tabular}


Table 2 Reliability analysis for the cantilever beam

\begin{tabular}{|c|c|c|c|c|c|c|c|}
\hline & $b(\mathrm{~mm})$ & $h(\mathrm{~mm})$ & $L(\mathrm{~mm})$ & $P_{x}(N)$ & $P_{y}(N)$ & $\beta^{L}$ & $\begin{array}{c}\text { Percentage } \\
\text { Decrease }\end{array}$ \\
\hline This work & 78.8211 & 25037.04 & 50200.9 & 1039.05 & 189.9932 & 78.8211 & - \\
\hline $\begin{array}{l}\text { Equivalent } \\
\text { model [39] }\end{array}$ & 75.7 & 27000 & 53000 & 1044.7 & 188.8 & 75.7 & $12.43 \%$ \\
\hline SSL [39] & 73.7 & 25080 & 50454.08 & 1046.8 & 188.3 & 73.7 & $18.54 \%$ \\
\hline
\end{tabular}

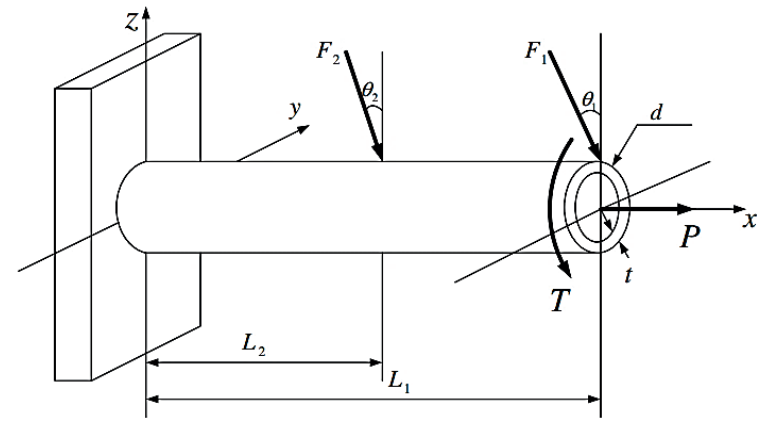

Fig. 4 A cantilever tube [39]

$g(\boldsymbol{X})=S_{y}-\sigma_{\max }$,

where $\sigma_{\max }$ is defined as follows:

$\sigma_{\max }=\sqrt{\sigma_{x}^{2}+3 \tau_{z x}^{2}}$

$\sigma_{x}=\frac{P+F_{1} \sin \theta_{1}+F_{2} \sin \theta_{2}}{A}+\frac{M c}{I}$.

$\sigma_{x}, \tau_{z x}, M, A$ and $I$ are respectively the normal stress, torsional stress, bending moment, area and moment of inertia; which can be given by:

$A=\frac{\pi}{4}\left[d^{2}-(d-2 t)^{2}\right]$

$M=F_{1} L_{1} \cos \theta_{1}+F_{2} L_{2} \cos \theta_{2}$

$I=\frac{\pi}{4}\left[d^{4}-(d-2 t)^{4}\right]$

$\tau_{z x}=\frac{T d}{4 I}$

$c=\frac{d}{2}$.

Uncertain variables are described in Table 3. In this problem parameters $t, d, P, T$ and $S_{y}$ are described by random variables, and $L_{1}$ and $L_{2}$ are treated as interval variables. According to the results which are shown in Table 4, our result is superior compared to those drawn from the literature in the sense of the reliability index.
Table 3 Uncertain variables for the cantilever beam

\begin{tabular}{|c|c|c|c|}
\hline $\begin{array}{l}\text { Type of } \\
\text { variable }\end{array}$ & Random variables & $\begin{array}{l}\text { Distribution } \\
\text { parameter } 1\end{array}$ & $\begin{array}{l}\text { Distribution } \\
\text { parameter } 2\end{array}$ \\
\hline \multirow{7}{*}{ Normal } & & $\mu$ & $\sigma$ \\
\hline & $t(\mathrm{~mm})$ & 5 & 0.1 \\
\hline & $d(\mathrm{~mm})$ & 42 & 0.5 \\
\hline & $P(\mathrm{~N})$ & 12000 & 1200 \\
\hline & $T($ N.m) & 90 & 9 \\
\hline & $S_{y}(\mathrm{MPa})$ & 220 & 22 \\
\hline & & Lower bound & Upper bound \\
\hline \multirow{3}{*}{ Interval } & $L_{1}(\mathrm{~mm})$ & 110 & 130 \\
\hline & $L_{2}(\mathrm{~mm})$ & 50 & 70 \\
\hline & & $A$ & B \\
\hline \multirow{3}{*}{ Uniform } & $\theta_{1}$ & 0 & 10 \\
\hline & $\theta_{2}$ & 5 & 15 \\
\hline & & $u$ & $\alpha$ \\
\hline \multirow{2}{*}{$\begin{array}{l}\text { Type I } \\
\text { extreme value }\end{array}$} & $F_{1}(\mathrm{~N})$ & 3000 & 300 \\
\hline & $F_{2}(\mathrm{~N})$ & 3000 & 300 \\
\hline
\end{tabular}

Cumulative distribution function for Type I extreme value and uniform distribution are $\exp \left[-\exp \left(-\frac{X-u}{\alpha}\right)\right]$ and $\frac{X-A}{B-A}$, respectively.

Table 4 Reliability analysis for the cantilever tube

\begin{tabular}{lccc}
\hline & This work & Equivalent model [39] & SSL [39] \\
\hline$\beta$ & 3.08 & 3.42 & 3.69 \\
Percentage & - & $-9.94 \%$ & $-16.53 \%$ \\
Decrease & & 4.97 & 4.97 \\
$t(\mathrm{~mm})$ & 4.98 & 41.70 & 41.70 \\
$d(\mathrm{~mm})$ & 41.77 & 12310.00 & 12338.00 \\
$P(\mathrm{~N})$ & 12258.46 & 90.00 & 90.00 \\
$T(\mathrm{~N} . \mathrm{m})$ & 90.15 & 168.00 & 162.00 \\
$S_{y}(\mathrm{MPa})$ & 169.80 & 4.92 & 4.93 \\
$\theta_{1}$ & 4.97 & 9.90 & 9.91 \\
$\theta_{2}$ & 9.97 & 130.00 & 125.00 \\
$L_{1}(\mathrm{~mm})$ & 122.88 & 70.00 & 65.00 \\
$L_{2}(\mathrm{~mm})$ & 62.38 & 3436.00 & 3473.00 \\
$F_{1}(\mathrm{~N})$ & 3989.39 & 3468.00 & 3472.00 \\
$F_{2}(\mathrm{~N})$ & 3334.55 & & \\
\hline
\end{tabular}




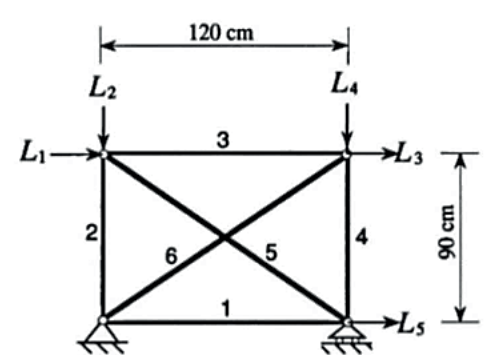

Fig. 5 Statically indeterminate 6-member truss structure [62]

\subsubsection{Statically indeterminate 6-member truss structure}

In this example, we consider a statically indeterminate 6-member truss with one degree of redundancy as shown in Fig. 5. The material density and the modulus of elasticity are respectively $2700 \mathrm{~kg} / \mathrm{m}^{3}$ and $70.6 \mathrm{GPa}$. The cross-sectional areas of the members are equal to $2.3 \mathrm{~cm}^{2}$ [62]. It is assumed that the yield stress and applied loads are statically independent with normal distribution. Table 5 shows the distribution parameters of uncertain variables.

Since it is a statically indeterminate structure, we use branch and bound method to determine failure paths and their corresponding failure probabilities. Due to the uncertain applied loads and yield stresses, members may probably fail in tension or compression. There are 30 potential failure modes for this structure, e.g. $\left(2^{+} \rightarrow 6^{+}\right),\left(5^{-} \rightarrow 6^{+}\right)$, etc., where superscripts + and - indicate tension and compression, respectively.

The dominant failure modes and their corresponding $\beta$-value are listed in Table 6 . As can be observed from the percentage change in this table, our results are better than or equal to those reported in the work by Shao and Murotsu [62] in term of the reliability index of each failure path.

\subsection{System reliability based design optimization with interval variables}

In order to performing system RBDO, the branch and bound method and an equivalent model are utilized to determine the system failure probability of each individual in the ICDE algorithm (i.e. each solution candidate). It should be noted that the failure probability of the structural system $P_{\text {sys }}$ should be less than or equal to the target system failure probability $P_{s y s}^{t}$.

\subsubsection{Statically indeterminate 6-member truss structure} In this example, the system RBDO of the 6-member truss structure shown in Fig. 5 is investigated. The cross-sectional areas are continuous variables which are taken from the interval $[0,10][1]$. By assuming that the yield stress and applied loads are statistically independent normal
Table 5 Distribution parameters for uncertain variables of statically indeterminate 6-member truss structure [62]

\begin{tabular}{lcccc}
\hline \multicolumn{2}{c}{ Variable } & Distribution & $\mu$ & $\begin{array}{c}\text { Coefficient of } \\
\text { variation }\end{array}$ \\
\hline \multirow{2}{*}{ Load $(\mathrm{KN})$} & $\mathrm{L}_{1}$ & Normal & 50 & 0.2 \\
& $\mathrm{~L}_{2}, \mathrm{~L}_{4}$ & Normal & 50 & 0.2 \\
& $\mathrm{~L}_{3}, \mathrm{~L}_{5}$ & Normal & 50 & 0.2 \\
$\begin{array}{l}\text { Yield stress } \\
\left(\mathrm{KN} / \mathrm{cm}^{2}\right)\end{array}$ & $\sigma_{\text {yield }}$ & Normal & 27.60 & 0.05 \\
\hline
\end{tabular}

Table 6 Dominant failure modes for statically indeterminate 6-member truss structure

\begin{tabular}{cccc}
\hline Failure path & This work & Ref [62] & Percentage change \\
\hline $2^{+} \rightarrow 6^{+}$ & 3.05273 & 3.05279 & -0.00197 \\
$1^{+} \rightarrow 6^{+}$ & 3.44798 & 3.44789 & 0.00261 \\
$5^{-} \rightarrow 6^{+}$ & 4.87714 & 4.87714 & 0 \\
$2^{+} \rightarrow 3^{+}$ & 6.99760 & 6.99763 & -0.00043 \\
$1^{+} \rightarrow 3^{-}$ & 8.12484 & 8.12484 & 0 \\
$3^{-} \rightarrow 5^{-}$ & 9.97030 & 9.97309 & -0.02798 \\
$2^{+} \rightarrow 4^{-}$ & 10.08970 & 10.08970 & 0 \\
$1^{+} \rightarrow 4^{-}$ & 11.18300 & 11.18300 & 0 \\
$4^{-} \rightarrow 5^{-}$ & 12.65880 & 12.65880 & 0 \\
$4^{+} \rightarrow 6^{+}$ & 15.02090 & 15.02090 & 0 \\
\hline
\end{tabular}

random variables, for two values of $P_{s y s}^{t}$, weight optimization of the structure is performed under different cases of interval variables.

As shown in Table 7, each case indicates that which variable is defined by an interval. They are defined as follows: (1) the yield stress of the members (2) the external loads (3) both of the yield stress of the members and external loads. Note that when uncertainty level $(\alpha)$ is equal to zero, the corresponding variable is treated as a random variable with normal distribution.

The results are presented in Tables 8-9 and Figs. 6-7. Note that the percentage values in tables indicate the percentage change in the optimum weight for different levels of uncertainty. It can be found that for both values of $P_{s y s}^{t}$, the optimum weight of the structure shows a falling-rising behavior by increasing the uncertainty level value.

Since the interval variables are changed to the corresponding uniform distributions (see Section 3.2) and the equivalent mean and equivalent standard deviation of variables with non-normal distribution are used in the FORM (see Section 3.1), this behavior can be traced to the equivalent standard deviation. It should be noted that the equivalent mean of a variable with uniform distribution is the same as the mean value of a variable with normal distribution. 
Table 7 Uncertain variables for the 6-member truss structure

\begin{tabular}{|c|c|c|c|c|c|}
\hline \multirow{2}{*}{ Case \# } & \multirow{2}{*}{\multicolumn{2}{|c|}{ Variable }} & \multirow{2}{*}{ Interval } & \multicolumn{2}{|c|}{ Normal Distribution } \\
\hline & & & & $\mu$ & Coefficient of variation \\
\hline \multirow{4}{*}{1} & \multirow{3}{*}{ Load $(\mathrm{kN})$} & $L_{1}$ & - & 50 & 0.2 \\
\hline & & $L_{2}, L_{3}$ & - & 30 & 0.2 \\
\hline & & $L_{4}, L_{5}$ & - & 20 & 0.2 \\
\hline & Yield stress $\left(\mathrm{kN} / \mathrm{cm}^{2}\right)$ & $\sigma_{\text {yield }}$ & {$[27.6(1-\alpha), 27.6(1+\alpha)]$} & - & - \\
\hline \multirow{4}{*}{2} & \multirow{3}{*}{ Load $(\mathrm{kN})$} & $L_{1}$ & {$[50(1-\alpha), 50(1+\alpha)]$} & - & - \\
\hline & & $L_{2}, L_{3}$ & {$[30(1-\alpha), 30(1+\alpha)]$} & - & - \\
\hline & & $L_{4}, L_{5}$ & {$[30(1-\alpha), 30(1+\alpha)]$} & - & - \\
\hline & Yield stress $\left(\mathrm{kN} / \mathrm{cm}^{2}\right)$ & $\sigma_{\text {yield }}$ & - & 27.60 & 0.05 \\
\hline \multirow{4}{*}{3} & \multirow{3}{*}{ Load $(\mathrm{kN})$} & $L_{1}$ & {$[50(1-\alpha), 50(1+\alpha)]$} & - & - \\
\hline & & $L_{2}, L_{3}$ & {$[30(1-\alpha), 30(1+\alpha)]$} & - & - \\
\hline & & $L_{4}, L_{5}$ & {$[30(1-\alpha), 30(1+\alpha)]$} & - & - \\
\hline & Yield stress $\left(\mathrm{kN} / \mathrm{cm}^{2}\right)$ & $\sigma_{\text {vield }}$ & {$[27.6(1-\alpha), 27.6(1+\alpha)]$} & - & - \\
\hline
\end{tabular}

$\alpha$ is the uncertainty level

Table 8 System reliability based design optimization of the 6-member truss structure with

\begin{tabular}{|c|c|c|c|c|c|c|c|}
\hline$\alpha(\%)$ & 0 & 5 & 10 & 15 & 20 & 25 & Case \# \\
\hline \multirow{3}{*}{ Weight (kg) } & 3.610 & $3.579(-0.9 \%)$ & $3.627(0.5 \%)$ & $3.709(2.7 \%)$ & $3.825(6.0 \%)$ & $3.978(10.2 \%)$ & 1 \\
\hline & 3.610 & $2.861(-20.7 \%)$ & $2.861(-20.7 \%)$ & $3.082(-14.6 \%)$ & $3.213(-11.0 \%)$ & $3.345(-7.3 \%)$ & 2 \\
\hline & 3.610 & $2.772(-23.2 \%)$ & $2.993(-17.1 \%)$ & $3.230(-10.5 \%)$ & $3.482(-3.5 \%)$ & $3.761(4.2 \%)$ & 3 \\
\hline
\end{tabular}

Table 9 System reliability based design optimization of the 6-member truss structure with

\begin{tabular}{|c|c|c|c|c|c|c|c|}
\hline$\alpha(\%)$ & 0 & 5 & 10 & 15 & 20 & 25 & Case \# \\
\hline \multirow{3}{*}{ Weight $(\mathrm{kg})$} & 3.958 & $3.907(-1.3 \%)$ & $3.984(0.7 \%)$ & $4.116(4.0 \%)$ & $4.310(8.9 \%)$ & $4.576(15.6 \%)$ & 1 \\
\hline & 3.958 & $2.970(-25.0 \%)$ & $3.100(-21.7 \%)$ & $3.256(-17.7 \%)$ & $3.426(-13.4 \%)$ & $3.605(-8.9 \%)$ & 2 \\
\hline & 3.958 & $2.842(-28.2 \%)$ & $3.145(-20.5 \%)$ & $3.477(-12.2 \%)$ & $3.853(-2.7 \%)$ & $4.287(8.3 \%)$ & 3 \\
\hline
\end{tabular}

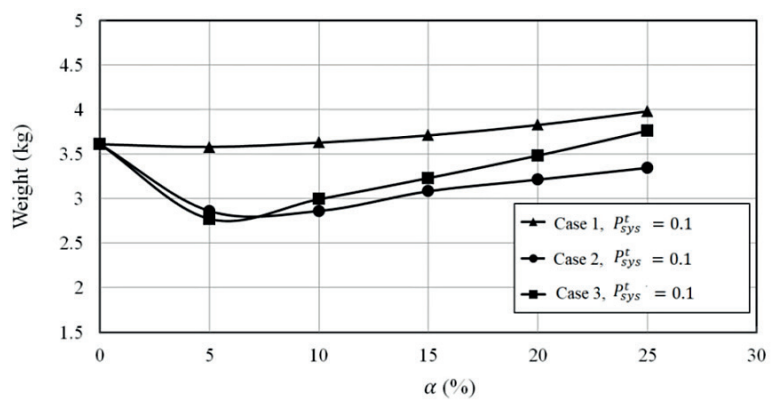

Fig. 6 Effect of the uncertainty levels on the optimum weight of the 6-member truss structure with $P_{s y s}^{t}=0.1$

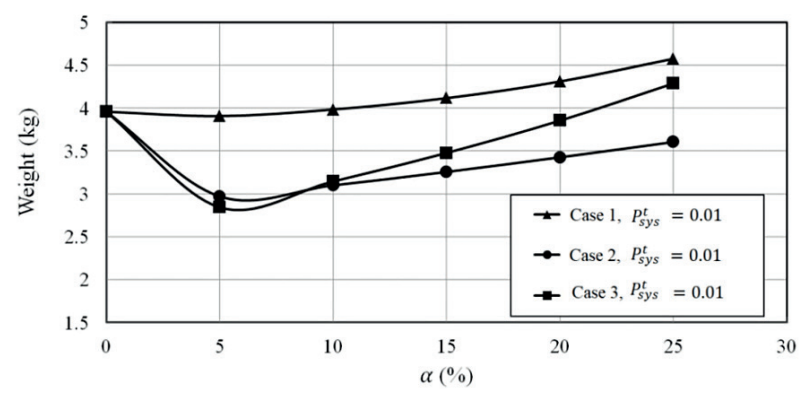

Fig. 7 Effect of the uncertainty levels on the optimum weight of the 6-member truss structure with $P_{s y s}^{t}=0.01$
For each case and $P_{f}^{\max }=0.1$, the changes of equivalent standard deviation $\left(\sigma_{e q}\right)$ are presented in Figs. 8-10. Variables with numbers 1 to 6 are related to the yield stress of members of the truss; and those with numbers 7 to 11 are corresponded to the applied loads. Note that for $\alpha=0$, all uncertain variables have normal distributions and there is no interval variables.

For case 1 in Fig. 8, it can be observed that there is a direct relationship between the $\sigma_{e q}$ and optimum weight of the structure. For a certain value of $\alpha$, if the equivalent standard deviation is less than the corresponding value for $\alpha=0$, the optimum weight decreases. For instance, from $\alpha=0 \%$ to $\alpha=5 \%$,the optimin weight is decreased from 3.610 to 3.578 due to the reduction of $\sigma_{e q}$. On the contrary, for $\alpha \geq 10 \%$, the optimin weight is increased by increasing the equivalent standard deviation. Similar behavior can be seen for case 2 in Fig. 9, where applied loads are defined with intervals. In this case, decreasing of the optimum weight is occurred for $\alpha \geq 5 \%$.

From Fig. 10 for case 3, for all values of $\alpha$, the equivalent standard deviations of the applied loads indicates a 


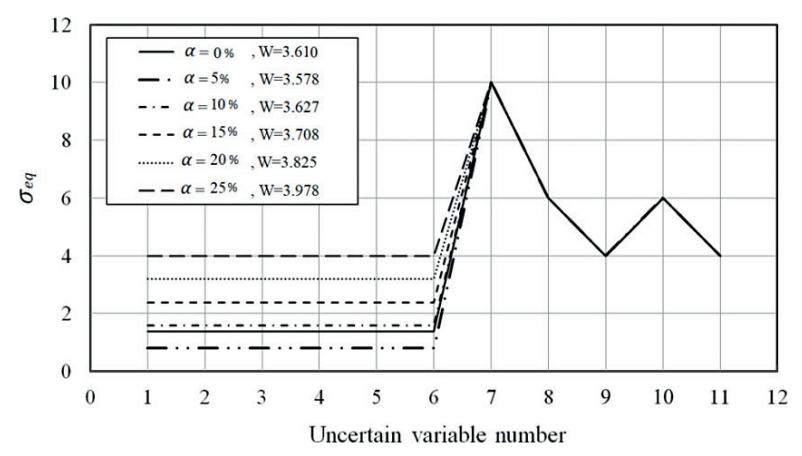

Fig. 8 Effect of the equivalent standard deviation on the optimum weight of the 6-member truss structure with $P_{s y s}^{t}=0.1$ case 1

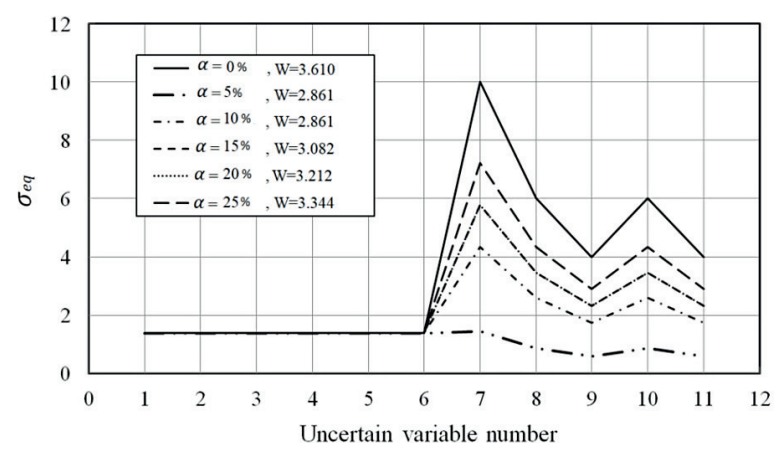

Fig. 9 Effect of the equivalent standard deviation on the optimum weight of the 6-member truss structure with $P_{s y s}^{t}=0.1$ for case 2

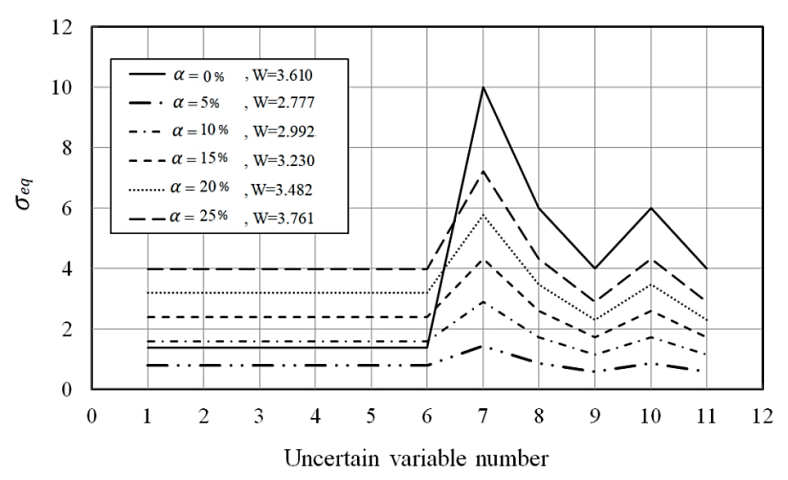

Fig. 10 Effect of the equivalent standard deviation on the optimum weight of the 6-bar truss structure with $P_{s y s}^{t}=0.1$ for case 3 reduction behavior, while those of the yield stress of the members are decreased only for $\alpha \leq 5 \%$. In this case, decreasing of the optimum is observed for the uncertainty levels between $5 \%$ to $20 \%$.

\subsubsection{Statically indeterminate 16-member truss structure}

Consider a statically indeterminate 16-member truss with three degree of redundancy shown in Fig. 11. The Young's Modulus $E$, the density $\rho$, and the lengths $L_{1}$ and $L_{2}$ are respectively $206 \mathrm{GPa}, 2700 \mathrm{~kg} / \mathrm{m}^{3}, 121.9 \mathrm{~cm}$ and $91.44 \mathrm{~cm}$ [21]. The cross-sectional areas are continues design variables taken from $[0,15]$. Uncertain variables are listed in Table 10 and it is assumed that the yield stress and applied loads are statistically independent. For two values of $P_{s y s}^{t}$, the size optimization of the truss structure is performed under the same cases that defined in the previous example.

For different uncertainty levels, the optimum weight and cross sectional areas of the structure are presented in Tables 11-13. In addition, the changes of the optimum weight with respect to changes in uncertainty level are shown in Figs. 12-13.

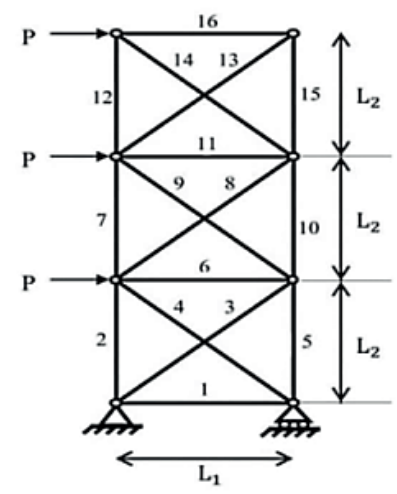

Fig. 11 Statically indeterminate 16-member truss structure [21]

Table 10 Uncertain variables for the 6-member truss structure

\begin{tabular}{cccccc}
\hline \multirow{2}{*}{ Case \# } & \multicolumn{2}{c}{ Variable } & Interval & \multicolumn{2}{c}{ Normal Distribution } \\
& & & & $\mu$ & Coefficient of variation \\
\hline \multirow{2}{*}{1} & Load $(\mathrm{kN})$ & $P$ & - & 44.45 & 0.1 \\
& Yield stress $\left(\mathrm{kN} / \mathrm{cm}^{2}\right)$ & $\sigma_{\text {yield }}$ & {$[27.6(1-\alpha), 27.6(1+\alpha)]$} & - & - \\
2 & Load $(\mathrm{kN})$ & $P$ & {$[44.45(1-\alpha), 44.45(1+\alpha)]$} & - & - \\
& Yield stress $\left(\mathrm{kN} / \mathrm{cm}^{2}\right)$ & $\sigma_{\text {yield }}$ & - & 27.60 & - \\
& Load $(\mathrm{kN})$ & $P$ & {$[44.45(1-\alpha), 44.45(1+\alpha)]$} & - & - \\
\hline
\end{tabular}


Table 11 System reliability based design optimization of the 16-member truss structure for case 1

\begin{tabular}{|c|c|c|c|c|c|c|c|c|c|c|c|c|}
\hline \multirow{2}{*}{$\begin{array}{l}P_{s y s}^{t} \\
\alpha(\%)\end{array}$} & \multicolumn{6}{|c|}{$10^{-1}$} & \multicolumn{6}{|c|}{$10^{-5}$} \\
\hline & 0 & 5 & 10 & 15 & 20 & 25 & 0 & 5 & 10 & 15 & 20 & 25 \\
\hline$A_{1}$ & 2.904 & 1.667 & 1.444 & 2.848 & 1.730 & 2.159 & 3.525 & 2.373 & 2.553 & 2.719 & 3.529 & 4.257 \\
\hline$A_{2}$ & 6.926 & 5.638 & 5.464 & 6.682 & 6.447 & 6.946 & 9.461 & 6.826 & 7.285 & 8.111 & 9.909 & 11.723 \\
\hline$A_{3}$ & 4.222 & 4.979 & 5.474 & 4.167 & 6.049 & 6.048 & 5.606 & 5.073 & 5.306 & 6.041 & 6.447 & 7.811 \\
\hline$A_{4}$ & 3.529 & 2.033 & 1.814 & 3.396 & 2.070 & 2.538 & 4.305 & 2.932 & 3.132 & 3.340 & 4.267 & 5.060 \\
\hline$A_{5}$ & 7.440 & 7.398 & 7.761 & 7.280 & 8.724 & 9.076 & 9.983 & 8.121 & 8.678 & 9.940 & 11.445 & 14.439 \\
\hline$A_{6}$ & 1.097 & 1.406 & 1.313 & 1.203 & 2.288 & 2.022 & 0.979 & 1.029 & 1.191 & 1.485 & 1.473 & 2.217 \\
\hline$A_{7}$ & 3.844 & 3.607 & 4.140 & 3.657 & 4.048 & 4.660 & 5.273 & 4.149 & 4.341 & 4.860 & 5.757 & 6.967 \\
\hline$A_{8}$ & 2.309 & 1.484 & 0.955 & 2.363 & 2.036 & 2.034 & 2.280 & 1.645 & 1.939 & 2.141 & 2.398 & 3.138 \\
\hline$A_{9}$ & 3.338 & 3.358 & 4.150 & 3.046 & 3.573 & 4.123 & 4.700 & 3.911 & 4.024 & 4.403 & 5.149 & 5.893 \\
\hline$A_{10}$ & 3.165 & 2.472 & 2.198 & 3.249 & 3.211 & 3.407 & 3.668 & 2.845 & 3.145 & 3.469 & 3.904 & 4.654 \\
\hline$A_{11}$ & 0.379 & 0.598 & 0.628 & 0.377 & 0.700 & 0.995 & 0.657 & 0.686 & 0.568 & 0.588 & 0.788 & 1.349 \\
\hline$A_{12}$ & 1.673 & 1.298 & 0.985 & 1.692 & 1.813 & 1.991 & 1.797 & 1.475 & 1.546 & 1.687 & 1.881 & 2.444 \\
\hline$A_{13}$ & 0.431 & 0.515 & 1.165 & 0.258 & 0.360 & 0.457 & 0.993 & 0.695 & 0.794 & 0.924 & 1.156 & 1.366 \\
\hline$A_{14}$ & 2.622 & 2.155 & 1.601 & 2.764 & 2.852 & 3.043 & 2.833 & 2.407 & 2.496 & 2.699 & 2.976 & 3.703 \\
\hline$A_{15}$ & 0.277 & 0.325 & 0.720 & 0.162 & 0.240 & 0.306 & 0.653 & 0.475 & 0.493 & 0.592 & 0.738 & 0.905 \\
\hline$A_{16}$ & 0.354 & 0.411 & 0.897 & 0.230 & 0.303 & 0.383 & 0.827 & 0.577 & 0.639 & 0.761 & 0.952 & 1.132 \\
\hline weight (kg) & 14.085 & $\begin{array}{c}12.440 \\
(-11.7 \%)\end{array}$ & $\begin{array}{l}12.897 \\
(-8.4 \%)\end{array}$ & $\begin{array}{c}13.724 \\
(-2.6 \%)\end{array}$ & $\begin{array}{l}14.667 \\
(4.1 \%)\end{array}$ & $\begin{array}{c}15.850 \\
(12.5 \%)\end{array}$ & 18.108 & $\begin{array}{c}14.290 \\
(-21.1 \%)\end{array}$ & $\begin{array}{c}15.201 \\
(-16.1 \%)\end{array}$ & $\begin{array}{c}16.946 \\
(-6.4 \%)\end{array}$ & $\begin{array}{c}19.73 \\
(9.0 \%)\end{array}$ & $\begin{array}{r}24.199 \\
(33.6)\end{array}$ \\
\hline
\end{tabular}

Table 12 System reliability based design optimization of the 16 -member truss structure for case 2

\begin{tabular}{|c|c|c|c|c|c|c|c|c|c|c|c|c|}
\hline \multirow{2}{*}{$\begin{array}{l}P_{s y s}^{t} \\
\alpha(\%)\end{array}$} & \multicolumn{6}{|c|}{$10^{-1}$} & \multicolumn{6}{|c|}{$10^{-5}$} \\
\hline & 0 & 5 & 10 & 15 & 20 & 25 & 0 & 5 & 10 & 15 & 20 & 25 \\
\hline$A_{1}$ & 2.904 & 1.963 & 1.700 & 1.836 & 2.868 & 2.541 & 3.525 & 2.914 & 2.845 & 3.081 & 3.116 & 3.531 \\
\hline$A_{2}$ & 6.926 & 6.000 & 5.886 & 6.205 & 6.903 & 7.006 & 9.461 & 8.414 & 8.409 & 8.809 & 9.066 & 9.471 \\
\hline$A_{3}$ & 4.222 & 5.235 & 5.545 & 5.502 & 4.400 & 4.855 & 5.606 & 5.787 & 6.064 & 6.051 & 6.305 & 6.166 \\
\hline$A_{4}$ & 3.529 & 2.299 & 2.063 & 2.246 & 3.460 & 3.228 & 4.305 & 3.558 & 3.499 & 3.736 & 3.812 & 4.239 \\
\hline$A_{5}$ & 7.440 & 7.791 & 8.109 & 8.095 & 7.594 & 8.075 & 9.983 & 9.986 & 10.251 & 10.360 & 10.725 & 10.800 \\
\hline$A_{6}$ & 1.097 & 1.823 & 1.814 & 1.793 & 1.160 & 1.302 & 0.979 & 1.371 & 1.455 & 1.361 & 1.449 & 1.615 \\
\hline$A_{7}$ & 3.844 & 3.630 & 3.885 & 3.990 & 4.011 & 4.306 & 5.273 & 4.854 & 4.994 & 5.159 & 5.342 & 5.401 \\
\hline$A_{8}$ & 2.309 & 2.002 & 1.693 & 1.808 & 2.349 & 2.105 & 2.280 & 2.047 & 2.088 & 2.160 & 2.312 & 2.705 \\
\hline$A_{9}$ & 3.338 & 3.201 & 3.616 & 3.658 & 3.423 & 3.800 & 4.700 & 4.389 & 4.486 & 4.641 & 4.797 & 4.734 \\
\hline$A_{10}$ & 3.165 & 2.837 & 2.701 & 2.868 & 3.187 & 3.215 & 3.668 & 3.200 & 3.328 & 3.530 & 3.766 & 4.236 \\
\hline$A_{11}$ & 0.379 & 0.514 & 0.758 & 0.743 & 0.395 & 0.498 & 0.657 & 0.532 & 0.557 & 0.608 & 0.700 & 0.681 \\
\hline$A_{12}$ & 1.673 & 1.592 & 1.660 & 1.661 & 1.657 & 1.625 & 1.797 & 1.584 & 1.598 & 1.712 & 1.857 & 2.113 \\
\hline$A_{13}$ & 0.431 & 0.271 & 0.352 & 0.417 & 0.510 & 0.759 & 0.993 & 0.891 & 0.980 & 0.994 & 1.014 & 0.942 \\
\hline$A_{14}$ & 2.622 & 2.515 & 2.561 & 2.591 & 2.667 & 2.561 & 2.833 & 2.495 & 2.549 & 2.715 & 2.963 & 3.365 \\
\hline$A_{15}$ & 0.277 & 0.181 & 0.220 & 0.263 & 0.318 & 0.489 & 0.653 & 0.596 & 0.628 & 0.648 & 0.664 & 0.597 \\
\hline$A_{16}$ & 0.354 & 0.213 & 0.281 & 0.349 & 0.446 & 0.619 & 0.827 & 0.753 & 0.800 & 0.841 & 0.844 & 0.755 \\
\hline weight (kg) & 14.085 & $\begin{array}{c}13.311 \\
(-5.5 \%)\end{array}$ & $\begin{array}{l}13.557 \\
(-3.7 \%)\end{array}$ & $\begin{array}{l}13.928 \\
(-1.1 \%)\end{array}$ & $\begin{array}{l}14.362 \\
(2.0 \%)\end{array}$ & $\begin{array}{l}14.856 \\
(5.5 \%)\end{array}$ & 18.108 & $\begin{array}{c}16.789 \\
(-7.3 \%)\end{array}$ & $\begin{array}{c}17.164 \\
(-5.2 \%)\end{array}$ & $\begin{array}{c}17.750 \\
(-2.0 \%)\end{array}$ & $\begin{array}{l}18.491 \\
(2.1 \%)\end{array}$ & $\begin{array}{l}19.333 \\
(6.8 \%)\end{array}$ \\
\hline
\end{tabular}


Table 13 System reliability based design optimization of the 16-member truss structure for case 3

\begin{tabular}{|c|c|c|c|c|c|c|c|c|c|c|c|c|}
\hline \multirow{2}{*}{$\begin{array}{l}P_{s y s}^{t} \\
\alpha(\%)\end{array}$} & \multicolumn{6}{|c|}{$10^{-1}$} & \multicolumn{6}{|c|}{$10^{-5}$} \\
\hline & 0 & 5 & 10 & 15 & 20 & 25 & 0 & 5 & 10 & 15 & 20 & 25 \\
\hline$A_{1}$ & 2.904 & 2.143 & 2.406 & 2.005 & 1.784 & 2.363 & 3.525 & 2.236 & 2.516 & 2.606 & 3.463 & 4.430 \\
\hline$A_{2}$ & 6.926 & 5.504 & 5.996 & 6.199 & 6.411 & 7.415 & 9.461 & 5.928 & 6.986 & 7.899 & 9.900 & 12.309 \\
\hline$A_{3}$ & 4.222 & 3.815 & 3.989 & 5.064 & 6.056 & 6.053 & 5.606 & 4.146 & 4.780 & 6.066 & 6.721 & 8.024 \\
\hline$A_{4}$ & 3.529 & 2.649 & 2.918 & 2.411 & 2.105 & 2.787 & 4.305 & 2.794 & 3.100 & 3.175 & 4.156 & 5.208 \\
\hline$A_{5}$ & 7.440 & 6.244 & 6.741 & 7.713 & 8.705 & 9.224 & 9.983 & 6.753 & 7.952 & 9.892 & 11.782 & 14.913 \\
\hline$A_{6}$ & 1.097 & 0.644 & 0.903 & 1.442 & 2.187 & 1.958 & 0.979 & 0.723 & 0.991 & 1.539 & 1.662 & 2.231 \\
\hline$A_{7}$ & 3.844 & 3.263 & 3.466 & 3.965 & 4.265 & 4.806 & 5.273 & 3.444 & 3.955 & 4.806 & 5.813 & 7.279 \\
\hline$A_{8}$ & 2.309 & 1.322 & 1.772 & 1.664 & 2.016 & 2.148 & 2.280 & 1.367 & 1.791 & 2.070 & 2.535 & 3.263 \\
\hline$A_{9}$ & 3.338 & 3.126 & 3.139 & 3.646 & 3.769 & 4.240 & 4.700 & 3.291 & 3.666 & 4.328 & 5.110 & 6.203 \\
\hline$A_{10}$ & 3.165 & 2.195 & 2.575 & 2.763 & 3.228 & 3.540 & 3.668 & 2.263 & 2.888 & 3.316 & 4.078 & 5.059 \\
\hline$A_{11}$ & 0.379 & 0.411 & 0.323 & 0.764 & 0.818 & 1.031 & 0.657 & 0.373 & 0.390 & 0.544 & 0.751 & 1.241 \\
\hline$A_{12}$ & 1.673 & 1.124 & 1.283 & 1.569 & 1.836 & 2.071 & 1.797 & 1.110 & 1.328 & 1.605 & 2.006 & 2.628 \\
\hline$A_{13}$ & 0.431 & 0.470 & 0.469 & 0.422 & 0.424 & 0.573 & 0.993 & 0.646 & 0.747 & 0.895 & 1.139 & 1.468 \\
\hline$A_{14}$ & 2.622 & 1.791 & 2.084 & 2.480 & 2.889 & 3.172 & 2.833 & 1.758 & 2.175 & 2.597 & 3.150 & 3.969 \\
\hline$A_{15}$ & 0.277 & 0.290 & 0.298 & 0.268 & 0.273 & 0.375 & 0.653 & 0.401 & 0.454 & 0.580 & 0.754 & 1.009 \\
\hline$A_{16}$ & 0.354 & 0.407 & 0.389 & 0.343 & 0.352 & 0.472 & 0.827 & 0.505 & 0.593 & 0.752 & 0.955 & 1.231 \\
\hline weight (kg) & 14.085 & $\begin{array}{c}11.203 \\
(-20.5 \%)\end{array}$ & $\begin{array}{c}12.263 \\
(-13.0 \%)\end{array}$ & $\begin{array}{l}13.502 \\
(-4.1 \%)\end{array}$ & $\begin{array}{l}14.895 \\
(5.8 \%)\end{array}$ & $\begin{array}{l}16.496 \\
(17.1 \%)\end{array}$ & 18.108 & $\begin{array}{c}11.936 \\
(-34.1 \%)\end{array}$ & $\begin{array}{c}13.985 \\
(-22.8 \%)\end{array}$ & $\begin{array}{l}16.599 \\
(-8.3 \%)\end{array}$ & $\begin{array}{l}20.110 \\
(11.1 \%)\end{array}$ & $\begin{array}{l}25.247 \\
(39.4 \%)\end{array}$ \\
\hline
\end{tabular}

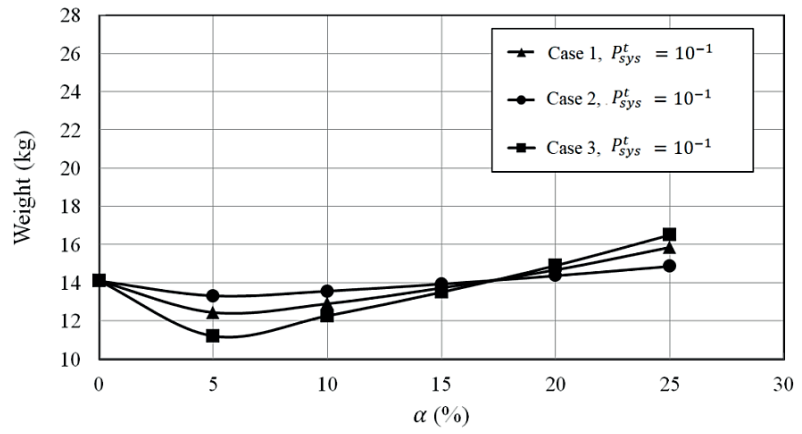

Fig. 12 Effect of the uncertainty levels on the optimum weight of the 16-member truss structure with $P_{s y s}^{t}=0.1$

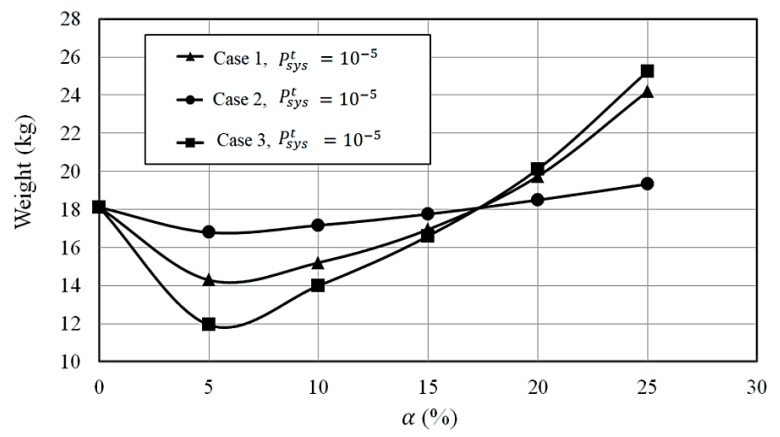

Fig. 13 Effect of the uncertainty levels on the optimum weight of the 16-member truss structure with $P_{s y s}^{t}=10^{-5}$
It can be see that the optimum weight of the structure is falling and then rising by increasing the uncertainty level. Therefore, it is affected not only by the uncertainty level but also by the equivalent standard deviation, like the previous example. For each case, increasing of the optimum weight is occurred for values of equal or greater than $20 \%$. In addition, the maximum and minimum reduction of the optimum weight is observed for $\alpha=0.05$ and, $\alpha=0.15$ respectively.

\section{Conclusions}

Traditional system reliability based design optimization (RBDO) of truss structures is generally focused on describing uncertainty by probability approach that requires a large amount of information to determine precise distributions of uncertain variables. In this study, the first hybrid uncertain model is applied to the system RBDO of trusses. All uncertain variables are described by random distributions but those lack information are defined by variation intervals. For all the considered structural problems, the effect of the uncertainty level on the optimum weight of the truss is investigated for different cases. Each case indicates that which variable, applied loads or yield stress of the members, is defined by an interval. The results show 
that the optimum weight of the structure is falling and then rising by increasing the uncertainty level. In order to investigate this behavior, the effect of the equivalent standard deviation on the optimum weight is considered. In our future work, we intend to consider both the first and

\section{References}

[1] Thoft-Christensen, P., Murotsu, Y. "Application of Structural Systems Reliability Theory", Springer, Berlin, Heidelberg, Germany 1986. https://doi.org/10.1007/978-3-642-82764-8

[2] Csébfalvi, A. "A New Theoretical Approach for Robust Truss Optimization with Uncertain Load Directions", Mechanics Based Design of Structures and Machines, 42(4), pp. 442-453, 2014. https://doi.org/10.1080/15397734.2014.880064

[3] Luo, X., Grandhi, R. V. "Astros for reliability-based multidisciplinary structural analysis and optimization", Computers \& Structures, 62(4), pp. 737-745, 1997. https://doi.org/10.1016/S0045-7949(96)00234-9

[4] Mathakari, S., Gardoni, P., Agarwal, P., Raich, A., Haukaas, T. "Reliability-Based Optimal Design of Electrical Transmission Towers Using Multi-Objective Genetic Algorithms", ComputerAided Civil and Infrastructure Engineering, 22(4), pp. 282-292, 2007. https://doi.org/10.1111/j.1467-8667.2007.00485.x

[5] Togan, V., Daloglu, A. T., Karadeniz, H. "Optimization of trusses under uncertainties with harmony search", Structural Engineering and Mechanics, 37(5), pp. 543-560, 2011. https://doi.org/10.12989/sem.2011.37.5.543

[6] Yang, I.-T., Hsieh, Y.-H. "Reliability-based design optimization with discrete design variables and non-smooth performance functions: AB-PSO algorithm", Automation in Construction, 20(5), pp. 610-619, 2011.

https://doi.org/10.1016/j.autcon.2010.12.003

[7] Shayanfar, M., Abbasnia, R., Khodam, A. "Development of a GA-based method for reliability-based optimization of structures with discrete and continuous design variables using OpenSees and Tcl", Finite Elements in Analysis and Design, 90, pp. 61-73, 2014. https://doi.org/10.1016/j.finel.2014.06.010

[8] Ho-Huu, V., Nguyen-Thoi, T., Le-Anh, L., Nguyen-Trang, T. "An effective reliability-based improved constrained differential evolution for reliability-based design optimization of truss structures", Advances in Engineering Software, 92, pp. 48-56, 2016.

https://doi.org/10.1016/j.advengsoft.2015.11.001

[9] Dizangian, B., Ghasemi, M. R. "An efficient method for reliable optimum design of trusses", Steel and Composite Structures, 21(5), pp. 1069-1084, 2016. https://doi.org/10.12989/scs.2016.21.5.1069

[10] Ho-Huu, V., Vo-Duy, T., Nguyen-Thoi, T., Ho-Nhat, L. "Optimization of truss structures with reliability-based frequency constraints under uncertainties of loadings and material properties", In: Bris, R., Snášel, V., Khanh, C. K., Dao, P. (eds.) Applied Mathematics in Engineering and Reliability, London, UK, 2016, pp. 59-65. https://doi.org/10.1201/b21348-11 second hybrid uncertain model to system RBDO problems of truss structures. In addition, we intend to use Ditlevsen's bound and consider the real statistical correlation between failure modes, because correlation between failure modes is neglected in Cornell's bound.

[11] Hamzehkolaei, N. S., Miri, M., Rashki, M. "An enhanced simulation-based design method coupled with meta-heuristic search algorithm for accurate reliability-based design optimization", Engineering with Computers, 32(3), pp. 477-495, 2016. https://doi.org/10.1007/s00366-015-0427-9

[12] Hamzehkolaei, N. S., Miri, M., Rashki, M. "An improved binary bat flexible sampling algorithm for reliability-based design optimization of truss structures with discrete-continuous variables", Engineering Computations, 35(2), pp. 641-671, 2018. https://doi.org/10.1108/EC-06-2016-0207

[13] Gomes, H. M., Corso, L. L. "A Hybrid Method for Truss Mass Minimization considering Uncertainties", Mathematical Problems in Engineering, 2017, Article ID 2324316, 2017. https://oi.org/10.1155/2017/2324316

[14] Ho-Huu, V., Le-Duc, T., Le-Anh, L., Vo-Duy, T., Nguyen-Thoi, T. "A global single-loop deterministic approach for reliability-based design optimization of truss structures with continuous and discrete design variables", Engineering Optimization, 50(12), pp. 20712090, 2018.

https://doi.org/10.1080/0305215X.2018.1428315

[15] Dimou, C. K., Koumousis, V. K. "Competitive genetic algorithms with application to reliability optimal design", Advances in Engineering Software, 34(11-12), pp. 773-785, 2003. https://doi.org/10.1016/S0965-9978(03)00101-7

[16] Dimou, C. K., Koumousis, V. K. "Reliability-Based Optimal Design of Truss Structures Using Particle Swarm Optimization", Journal of Computing in Civil Engineering, 23(2), pp.100-109, 2009. https://doi.org/10.1061/(ASCE)0887-3801(2009)23:2(100)

[17] Toğan, V., Daloğlu, A. "Reliability and Reliability-Based Design Optimization", Turkish Journal of Engineering and Environmental Sciences, 30, pp. 237-249, 2006. [online] Available at: https://dergipark.org.tr/tr/pub/tbtkengineering/issue/12150/145098 [Accessed: 20 October 2019]

[18] Hendawi, S., Frangopol, D. M. "Reliability-based Structural System Assessment, Design and Optimization System reliability and redundancy in structural design and evaluation", Structural Safety, 16, pp. 47-71, 1994.

[19] Natarajan, K., Santhakumar, A. R. "Reliability-based optimization of transmission line towers", Computers \& Structures, 55(3), pp. 387-403, 1995.

https://doi.org/10.1016/0045-7949(95)98866-O

[20] Thampan, C. K. P. V., Krishnamoorthy, C. S. "System ReliabilityBased Configuration Optimization of Trusses", Journal of Structural Engineering, 127(8), pp. 947-956, 2001. https://doi.org/10.1061/(ASCE)0733-9445(2001)127:8(947)

[21] Park, S., Choi, S. Sikorsky, C., Stubbs, N. "Efficient method for calculation of system reliability of a complex structure", International Journal of Solids and Structures, 41(18-19), pp. 5035-5050, 2004. https://doi.org/10.1016/j.ijsolstr.2004.04.028 
[22] Nguyen, T. H., Song, J., Paulino, G. H. "Single-Loop System Reliability-Based Design Optimization Using Matrix-Based System Reliability Method: Theory and Applications", Journal of Mechanical Design, 132(1), Article number: 011005, 2010. https://doi.org/10.1115/1.4000483

[23] Liu, Y., Lu, N., Yin, X. "A Hybrid Method for Structural System Reliability-Based Design Optimization and its Application to Trusses", Quality and Reliability Engineering International, 32(2), pp. 595-608, 2016. https://doi.org/10.1002/qre.1775

[24] Okasha, N. M. "Proposed Algorithms for an Efficient System Reliability-Based Design Optimization of Truss Structures", Journal of Computing in Civil Engineering, 30(5), 2016. https://doi.org/10.1061/(ASCE)CP.1943-5487.0000569

[25] Hamedani, K. B., Kalatjari, V. R. "Structural System Reliability Based Optimization of Truss Structures Using Genetic Algorithm", International Journal of Optimization in Civil Engineering, 8(4), pp. 565-586, 2018. [online] Available at: http://ijoce.iust.ac.ir/article-1363-en.html [Accessed: 30 October 2019]

[26] Csébfalvi, A. "Structural optimization under uncertainty in loading directions: Benchmark results", Advances in Engineering Software, 120, pp. 68-78, 2018. https://doi.org/10.1016/j.advengsoft.2016.02.006

[27] Csébfalvi, A. "A New Algorithm for Robust Truss Optimization: Benchmark Results", presented at: Proceedings of the Twelfth International Conference on Computational Structures Technology, Naples, Italy, Sept, 2-5, 2014. https://doi.org/10.4203/ccp.106.174

[28] Lógó, J., Rad, M. M., Tamássy, T., Knabel, J., Tauzowski, P. "Reliability Based Optimal Design of Frames with Limited Residual Strain Energy Capacity", In: Proceedings of the Twelfth International Conference on Civil, Structural and Environmental Engineering Computing, Civil-Comp Press, Stirlingshire, UK, 2009. https://doi.org/10.4203/ccp.91.52

[29] Lógó, J., Vásárhelyi, A., Rad, M. M., Stocki, R. "Reliability based limit analysis of steel frames with limited residual strain energy capacity", Proceedings in Applied Mathematics and Mechanics, Special Issue: 79th Annual Meeting of the International Association of Applied Mathematics and Mechanics, 8(1), pp. 10041-10044, 2008. https://doi.org/10.1002/pamm.200810041

[30] Lógó, J., Rad, M. M., Knabel, J., Tauzowski, P. "Reliability based design of frames with limited residual strain energy capacity", Periodica Polytechnica Civil Engineering, 55(1) , pp. 13-20, 2011. https://doi.org/10.3311/pp.ci.2011-1.02

[31] Macdonald, A. J. "Structure and Architecture", 2nd ed., Architectural Press, Oxford, UK, 2001.

[32] Ben-Haim, Y., Elishakoff, I. "Convex Models of Uncertainty in Applied Mechanics", 1st ed., North Holland Publishing, Amsterdam, Netherlands, 1990.

[33] Jiang, C., Li, W. X., Han, X., Liu, L. X., Le, P. H. "Structural reliability analysis based on random distributions with interval parameters", Computers \& Structures, 89(23-24), pp. 2292-2302, 2011. https://doi.org/10.1016/j.compstruc.2011.08.006
[34] Jiang, C., Zheng, J., Han, X. "Probability-interval hybrid uncertainty analysis for structures with both aleatory and epistemic uncertainties: a review", Structural and Multidisciplinary Optimization, 57(6), pp. 2485-2502, 2018.

https://doi.org/10.1007/s00158-017-1864-4

[35] Du, X., Sudjianto, A., Huang, B. "Reliability-Based Design With the Mixture of Random and Interval Variables", Journal of Mechanical Design, 127(6), pp. 1068-1076, 2005. https://doi.org/10.1115/1.1992510

[36] Du, X. "Interval Reliability Analysis", In: International Design Engineering Technical Conferences and Computers and Information in Engineering Conference, Las Vegas, NV, USA, pp. 1103-1109, 2007. https://doi.org/10.1115/DETC2007-34582

[37] Guo, J., Du, X. "Reliability sensitivity analysis with random and interval variables", International Journal for Numerical Methods in Engineering, 78(13), pp. 1585-1617, 2009. https://doi.org/10.1002/nme. 2543

[38] Qiu, Z., Wang, J. "The interval estimation of reliability for probabilistic and non-probabilistic hybrid structural system", Engineering Failure Analysis, 17(5), pp. 1142-1154, 2010. https://doi.org/10.1016/j.engfailanal.2010.01.010

[39] Jiang, C., Lu, G. Y., Han, X., Liu, L. X. "A new reliability analysis method for uncertain structures with random and interval variables", International Journal of Mechanics and Materials Design, 8(2), pp. 169-182, 2012. https://doi.org/10.1007/s10999-012-9184-8

[40] Xie, S., Pan, B., Du, X. "An efficient hybrid reliability analysis method with random and interval variables", Engineering Optimization, 48(9), pp. 1459-1473, 2016. https://doi.org/10.1080/0305215X.2015.1111084

[41] Elishakoff, I., Colombi, P. "Combination of probabilistic and convex models of uncertainty when scarce knowledge is present on acoustic excitation parameters", Computer Methods in Applied Mechanics and Engineering, 104(2), pp. 187-209, 1993. https://doi.org/10.1016/0045-7825(93)90197-6

[42] Elishakoff, I., Cai, G. Q., Starnes Jr, J. H. "Non-linear buckling of a column with initial imperfection via stochastic and non-stochastic convex models", International Journal of Non-Linear Mechanics, 29(1), pp. 71-82, 1994. https://doi.org/10.1016/0020-7462(94)90053-1

[43] Qiu, Z., Yang, D., Elishakoff, I. "Probabilistic interval reliability of structural systems", International Journal of Solids and Structures. 45(10), pp. 2850-2860, 2008.

https://doi.org/10.1016/j.ijsolstr.2008.01.005

[44] Jiang, C., Han, X., Li, W. X., Liu, J., Zhang, Z. "A Hybrid Reliability Approach Based on Probability and Interval for Uncertain Structures", Journal of Mechanical Design, 134(3), Article number: 031001, 2012. https://doi.org/10.1115/1.4005595

[45] Huang, Z. L., Jiang, C., Zhou, Y. S., Zheng, J., Long, X. Y. "Reliability-based design optimization for problems with interval distribution parameters", Structural and Multidisciplinary Optimization, 55(2), pp. 513-528, 2017. https://doi.org/10.1007/s00158-016-1505-3 
[46] Zaeimi, M., Ghoddosian, A. "Structural Reliability Assessment Based on the Improved Constrained Differential Evolution Algorithm", Periodica Polytechnica Civil Engineering, 62(2), pp. 494-507, 2018.

https://doi.org/10.3311/PPci.11537

[47] Jia, G., Wang, Y., Cai, Z., Jin, Y. "An improved $(\mu+\lambda)$-constrained differential evolution for constrained optimization", Information Sciences, 222, pp. 302-322, 2013. https://doi.org/10.1016/j.ins.2012.01.017

[48] Elegbede, C. "Structural reliability assessment based on particles swarm optimization", Structural Safety, 27(2), pp. 171-186, 2005. https://doi.org/10.1016/j.strusafe.2004.10.003

[49] Rosenblatt, M. "Remarks on a Multivariate Transformation", The Annals of Mathematical Statistics, 23(3), pp. 470-472, 1952. https://doi.org/10.1214/aoms/1177729394

[50] Nataf, A. "Determination of the distributions for given margins", Comptes Rendus de l'Académie des Sciences, 225, pp. 42-43, 1962. (in French)

[51] Ang, A. H.-S., Tang, W. H. "Probability Concepts in Engineering: Emphasis on Applications to Civil and Environmental Engineering", 2nd ed., Wiley, New York, NY, USA, 2007.

[52] Hasofer, A. M., Lind, N. C. "Exact and invariant second moment code format", Journal of the Engineering Mechanics Division, 100(1), pp. 111-121, 1974.

[53] Nowak, A. S., Collins, K. R. "Reliability of Structures", 1st ed., McGraw-Hill, Boston, MA, USA, 2000.

[54] Nocedal, J., Wright, S. J. "Numerical Optimization", Springer, New York, NY, USA, 1999.

https://doi.org/10.1007/978-0-387-40065-5
[55] Cornell, C. A. "Bounds on the Reliability of Structural Systems", Journal of the Structural Division, 93(1), pp. 171-200, 1967.

[56] Ditlevsen, O. "Narrow Reliability Bounds for Structural Systems", Journal of Structural Mechanics, 7(4), pp. 453-472, 1979. https://doi.org/10.1080/03601217908905329

[57] Kharmanda, G., El Hami, A., De Cursi, E. S. "Reliability-based Design Optimization (RBDO)", In: Breitkopf, P., Coelho, R. F. (eds.) Multidisciplinary Design Optimization in Computational Mechanics, Wiley, Hoboken, NJ, USA, 2013. pp. 425-458. https://doi.org/10.1002/9781118600153.ch11

[58] Tsompanakis, Y., Lagaros, N. D., Papadrakakis, M. "Structural Design Optimization Considering Uncertaintie", 1st ed., Taylor \&Francis, Boca Raton, FL, USA, 2008.

[59] Togan, V., Daloglu, A. T. "Reliability and Reliability-Based Design Optimization", Turkish Journal of Engineering and Environmental Sciences, 30(4), pp. 237-249, 2006.

[60] Cheng, G., Xu, L., Jiang, L. "A sequential approximate programming strategy for reliability-based structural optimization", Computers \& Structures, 84(21), pp. 1353-1367, 2006. https://doi.org/10.1016/j.compstruc.2006.03.006

[61] Kuschel, N., Rackwitz, R. "Two basic problems in reliability-based structural optimization", Mathematical Methods of Operations Research, 46(3), pp. 309-333, 1997. https://doi.org/10.1007/BF01194859

[62] Shao, S., Murotsu, Y. "Approach to failure mode analysis of large structures", Probabilistic Engineering Mechanics, 14(1-2), pp. 169$177,1999$.

https://doi.org/10.1016/S0266-8920(98)00028-9 